\title{
Nitel Araştırma Yöntemlerinden İz Sürme (Tracer) ve Kan Transfüzyonu Sürecinde Bir Uygulama Örneği
}

\author{
Tracer Method from Qualitative Research Methods and an Application Example in Blood \\ Transfusion Process
}

\author{
Nesrin ÖZCAN
}

ÖZ

İz sürme/ Süreç izleme yöntemi, tek bir durumun ya da az sayıda vakanın incelendiği genellikle nedensel mekanizmaları inceleyen nitel bir araştırma yöntemidir. Veri toplama ve örneklemenin güvenilirliğini sağlama amacına yönelik bir yöntemdir.

Ulusal literatürde özellikle sosyal bilimlerde yöntemin uygulandığı çalışmalar görülmekle birlikte bu çalışmada belirtilen detayda yöntemin açıklaması yapılmamıştır. Bu çalışmada iz sürme yöntemi ile ilgili genel bilgiler detaylı olarak açıklanmış, 500 yatak üzerinde bir hastanedeki kan transfüzyon süreci iz sürme yöntemine örnek oluşturacak şekilde incelenmiştir. Hastane kan transfüzyon merkezi ve kan transfüzyonu uygulanan hasta servislerinde görüşmeler ve gözlemler yapılmıştır. Denetim anında bu birimlerde bulunan kan transfüzyonu sürecine ilişkin doküman ve kayıtlardan yararlanılmıştır ve geçmişe dönük kan transfüzyonu yapılan hasta dosyaları incelenerek elde edilen bulgular değerlendirilmiştir.

Kan transfüzyonu süreci hem hasta izi sürme hem de sistemsel iz sürmenin birlikte gerçekleştirilmesine firsat veren bir süreçtir. Çalışmanın sonucunda iz sürme yönteminin anlaşılması hedeflenmiş uygulama örneğinde transfüzyon süreci ile ilgili bulgular yöntemin anlaşılmasını kolaylaştırılması açısından paylaşılmıştır.

Anahtar Kelimeler: İz Sürme Yöntemi, Süreç İzleme Yöntemi, Kan Transfüzyonu

Nesrin ÖZCAN (四)

Altınbaş Üniversitesi

e-posta:nesrin.ozcan@altinbas.edu.tr

\begin{abstract}
Tracer / process tracing is a qualitative research method that usually examines causal mechanisms in which a single case or a small number of cases are examined. It is a method for collecting data and ensuring the reliability of the sample.

In the national literature, although the studies in which the method has been applied in social sciences are observed, the method is not explained in detail in these studies. In this study, general information about the method of tracing is explained in detail and the blood transfusion process in a hospital over 500 beds has been examined as an example to the method of tracing. Interviews and observations were made at the hospital blood transfusion center and during blood transfusions. At the time of the assessment, documents and records about the blood transfusion process were used. The documents of the patients who had a blood transfusion were retrospectively examined and the findings from all of these surveys were evaluated.

The procedure of blood transfusion is a process that allows both patient-tracing and systemic tracing to be carried out together. As a result of the work the main target of the study was to provide understanding the method, findings of the transfusion process were shared to facilitate the understanding of the method.
\end{abstract}

Keywords: Tracer Method, Process Tracing Method, Blood Transfusion

\section{GíRiş}

Sosyal bilimler, karmaşıklık biçimleriyle boğuşmaya çalışırken, hem istatistiksel hem de kalitatif metodolojilerin geliştirilmesi gerekmektedir (1). İz sürme yöntemi; olayların süreçleri ve sekansları hakkında kanıtların analizi ya da olayı nedensel olarak açıklayabilecek nedensel mekanizmalarla ilgili hipotezler geliştirmeye ya da test etmeye yönelik nitel bir araştırma tekniğidir. İz sürme yöntemi son dönemlerde sosyal olayların açıklanmasında sıklıkla kullanılan bir yöntem olarak karşımıza çıkmaktadır. $\mathrm{Bu}$ çalışmanın amacı iz sürme yönteminin tanımlanması; türlerinin ve aşamalarının açıklanması ve sağlık alanında 
kan transfüzyonu sürecinin incelenmesi suretiyle bir örnekle yöntemin anlaşılmasının sağlanmasıdır.

1970'liyıllardasosyalolgularınincelenmesindekullanılmaya başlanan süreç izleme yöntemi, Alexander George ve Andrew Bennett'in 2005 tarihli Sosyal Bilimlerdeki Vaka Çalışmaları ve Teori Gelişimi metinlerinin yayınlanmasıyla nitel araştırmada giderek daha fazla kullanılan ve alıntılanan bir araç haline gelmiştir.

Sağlikta iz sürme yönteminin daha çok akreditasyon sürecinde bir değerlendirme metodu olarak kullanıldığı görülmektedir. Sağlıkta iz sürme; hasta izleme, sistem izleme ve multidisipliner iz sürme olarak karşımıza çıkmaktadır.

\section{YÖNTEM}

$\mathrm{Bu}$ araştırmada iz sürme yöntemi tanımlanarak kan transfüzyon süreci ile sistemsel iz sürmeye örnek bir uygulama sunulmuştur. İz sürme yöntemi ile ilgili PubMed, Google Scholar, Health Management Database, Science Direct veri tabanlarında 'tracer', 'process tracing', 'process tracing AND health' ve 'iz sürme' terimleri ile arama yaparak erişilen kaynaklardan elde edilen bilgiler derlenmiştir.

Örnek uygulama için Kan Transfüzyon Merkezi olan 500 yatak üzeri bir kamu hastanesinde gerçekleştirilen kan transfüzyonu süreci denetim raporundan faydalanılmıştır. Araştırmanın yapıldığı kuruma ilişkin bilgiler gizlilik sözleşmesi gereği bu çalışmada açıklanmamıştır.

Araştırmanın kısıtlı sürede yapılması ve bu süre içinde incelenmesi gereken bazı bilgilere ve görüşülmesi gereken bazı kişilere ulaşılamaması araştırmanın kısıtlarını oluşturmaktadır. $\mathrm{Bu}$ makalenin amacı kan transfüzyon süreci ile ilgili bulgular ile birlikte iz sürme yönteminin anlaşılmasını sağlamaktır.

Sağlıkta Akreditasyon Standartları'nda 'Transfüzyon öncesi, esnası ve sonrasında hasta güvenliğini sağlamaya yönelik tedbirler alınmaktadır.' Bu standardın hastanede karşılanma düzeyi iz sürme yöntemi kullanılarak ortaya konmaya çalışılmıştır.

Ulusal Kan ve Kan Ürünleri Rehberi ve Sağlikta Akreditasyon Standartlarında oluşturulması istenen dokümanlar incelenecek dokümanlar olarak belirlenmiştir. $\mathrm{Bu}$ kapsamda kurumda yürürlükte olan Kan Ürünleri Taşıma ve Kullanım Talimatı, Hasta Güvenliği Prosedürü ve Transfüzyon Merkezi Çalışma Prosedürü ve Kan Transfüzyon Merkezi Acil Hasta Talimatı dokümanları incelenmiş̧tir. Kanıt toplama ve örneklemin oluşturulması aşamalarında Dışarıdan Gelen Kan Kayıt Defteri, Servise Kan Teslim Defteri, Kan İmha Defteri, Kan İstem Formu, Kan ve Kan Ürünleri Transfüzyonu İzlem Formu ve Hastane Bilgi Yönetim Sisteminde bulunan kayttlardan faydalanılmıştır.

Kan transfüzyonu Komitesi ve tutanaklarında konu ile ilgili kararlar izlenmiştir.

Kliniklere erişimde kısıtlılıklar olması sebebi ile sahada çalışanların bu kararlar ve dokümanlarda belirtilen kurallar konusunda bilgi düzeyleri gözlenememiştir. Uygulama ile kararlar ve kuralların tutarlıllğı incelenmiştir.

Transfüzyon Güvenliğini riske atan uygunsuzluklar ve bunlara ilişkin düzeltici / önleyici faaliyetlerde yönetimin ve çalışanın katılımı değerlendirilmiştir. Hasta Güvenliği Komitesi toplantı tutanaklarına erişme imkanı bulunamamıştır.

Çalışanların eğitimlerle konu hakkında bilgilendirildiği belirtilmiştir. Yazılı eğitim materyalleri görülmüştür. (Kan ve Kan Ürünleri Klinik Kullanım Kılavuzu, Transfüzyon Pratiği) Ancak bu materyallerin çalışanlara teslimatına dair bir kayıt ya da eğitim katılım kayıtlarına ulaşma imkanı olmamıştır.

Kan transfüzyonu sürecini bütün olarak değerlendirmek üzere iz sürme yöntemi ile beş hasta dosyası incelenmiştir. $\mathrm{Bu}$ hastalar Kan Merkezi'nde bulunan kayıtlardan amaçlı örnekleme yöntemi ile belirlenmiştir. Daha fazla kan transfüzyonu uygulanan hasta dosyasına ulaşma imkanı olmadığından örneklem genişletilememiştir. $\mathrm{Bu}$ hasta dosyalarında;

- Tedavi Planlarında kan isteminin sorgulaması yapılmıştır.

- Transfüzyon İzlem Formları ile transfüzyon süreci incelenmiştir.

- Onam Formları değerlendirilmiştir.

- Hasta bakım planları kan transfüzyonu açısından incelenmiş̧ir.

- Tüm bu kayıtların birbiri ile tutarlılığı hasta bazında bilgiler takip edilerek değerlendirilmiştir.

Ayrica Servise Kan Teslim Defteri'nden alınan bilgiler doğrultusunda seçilen 20 hastaya ait Kan Transfüzyonu İzlem Formu incelenmiştir. 
Kan Transfüzyonu İzlem Formu transfüzyon sürecinde hasta güvenliği için kilit bir doküman olduğundan formda belirtilen tüm bilgilerin eksiksiz doldurulması ve gerekli doğrulamaların gerçekleştirilerek forma kaydının yapılması gerekmektedir (Form ekte sunulmuştur, Ek 1).

\section{1.İz Sürme Yöntemi ile İlgili Genel Bilgiler}

\section{1. İz Sürme Yöntemi}

İz sürme / süreç izleme yöntemi, tek bir durumun ya da az sayıda vakanın incelendiği genellikle nedensel mekanizmaları inceleyen nitel bir araştırma yöntemidir. Veri toplamak, aynı zamanda örneklemenin güvenilirliğini sağlamak amacına yönelik bir yöntem dir (2).

Hornby ve Symon iz sürme yöntemini "bazı etiketlerin (dokümanların) yardımıyla, belirli bir zaman diliminde ve ilgili gruplar üzerinde, örgütsel süreçlerin tanımlanması" olarak tanımlamıştır (3).

Süreç takibinin amacı iyi tanımlanmış ve spesifik olaylar ve süreçler hakkında bilgi elde etmektir. Süreç izleme, ideal olarak geniş bir yelpazedeki kaynaklardan büyük miktarlarda veri toplanmasını gerektirir. Temel amaç, daha geniş bir evrene yayılmak yerine, incelenen az sayıdaki vakadaki sonucu açıklamaktır (4). Süreç izleme, vaka çalışmalarının merkezinde yer alır ve nedensel çıkarım için vazgeçilmez bir araçtır (5).

Süreç izleme, tanımlayıcı ve nedensel çıkarımın temelini sağlayan tanısal kanıtlar bulmayı gerektirir. Araştırmacının, belirli bir kanıt parçasının tanısal olduğunu tespit edebilmesi, bu kanıt parçasından yola çıkarak hangi kanıt, olayları incelenmesi ve kimlerle görüşülmesi gerektiğini kestirebilmesi önceki bilgilerine ve araştırma yapılan konudaki tecrübesine dayanır (6). İz sürme tekniğini uygulayabilmek için incelenecek alanda derinlemesine bilgi sahibi olmak araştırmanın güvenilirliğini arttırmaktadır.

Süreç takibinde, araştırmacı, bir kuram varsaydığı veya bir olguda ima ettiği nedensel sürecin, bu durumda araya giren değişkenlerin sekansında ve değerlerinde açıkça görüp görmediğini görmek için, geçmişleri, arşiv belgelerini, görüşme transkriptlerini ve diğer kaynakları inceler. Aradaki nedensel süreci (nedensel zincir ve nedensel mekanizmayı) bağımsız bir değişken veya değişkenler arasında tanımlamaya çalışır (4).
Süreç izleme yöntemi, ilgi sürecinin her adımında nedensel mekanizmaları tanımlamak için muazzam miktarda veri gerektirir. Bu nedenle, tüm veri toplama seçeneklerinin dikkate alınması, güçlü yanlarını, zayıf yönlerini ve kullanım alanlarını ayrıntılı olarak incelemek önemlidir (4).

Bennet ve Checkel iz sürme yöntemini; vakaların süreçleri, sekansları ve olayları hakkında kanıtların analizi ya da olayı nedensel olarak açıklayabilecek nedensel mekanizmalarla ilgili hipotezler geliştirme ya da test etme amaçları olarak tanımlarlar ve iki yaklaşım sunarlar: Tümevarım ve tümdengelim (7).

\section{2. İz Sürme Yönteminin Tarihi Gelișimi}

1970'lerin başlarında Birleşik Devletlerde bilişsel psikoloji alanında "süreç izleme" terimi ortaya çıkmıştır. Psikolojide kullanıldığı şekliyle süreç izleme, sezgisel olarak daha iyi anlamak için bilişsel zihinsel süreçlerdeki ara basamakları incelemek için kullanılan tekniklere atıfta bulunmaktadır (7). Daha sonra sağlık alanında 1973'de Kessner tarafından kullanılmıştır (8).

1979 y1lında, Stanford Üniversitesi siyaset bilimcisi Alexander L. George, tarihsel açıklamalarla ilgili çıkarımlarda bulunmak için örnek olaylardan kanıt kullanımını tanımlamak için kullanmıştır (7).

Süreç izleme günümüzde incelenecek olay sayısı az olan çalışmalarda daha sık kullanılmaktadır. İstatistiksel analizlerin tek başına nedensel ilişkilerin ortaya çıkıp çıkmayacağı konusunda şüphelerin artması ile kalitatif değerlendirmenin de yapıldı $\breve{1} 1$ karma metodlar geliştirilmeye başlanmıştır (9). Bu yöntem, nitel araştırmada giderek daha fazla kullanılan ve alıntılanan bir araç haline gelmiştir; son zamanlarda Alexander George ve Andrew Bennett'in 2005 tarihli Sosyal Bilimlerdeki Vaka Çalışmaları ve Teori Gelişimi metinlerinin yayınlanmasıyla hızlanmıştır.

Sosyal bilimlerde onlarca yıldır uygulanmış olmasına rağmen, sadece son yıllarda siyasal bilimlerde metodolojik tartışmalarda iz sürme yönteminin ön plana çıktığ1 görülmüştür. Popülaritesine rağmen, metodolojisini resmileştirmek, standartlarını tanımlamak ve uygulanabilirlik aralığını tanımlamakta çok başarılı olunamamıştır (10).

Çalışmalara bakıldığında süreç izleme, geniş kapsamlı açıklamalar arasında hükme varmak için güçlü bir araç olarak yaygınlaştırılmış olsa da, literatür bu hedefin hizmetinde kapsamlı kılavuzlara sahip değildir ( 11). 


\section{3. İz Sürme Yöntemi Așamaları}

İz sürme yöntemi aşağıdaki aşamalardan oluşur:

- Etiketlerin tanımlanması: İzlenmesi planlanan sürece ilişkin incelenecek dokümanların belirlenmesidir.

- Örneklemin belirlenmesi: Araştırma konusuna yönelik örneklemin seçilmesidir.

- Etiketlerin kontrolü: Belirlenmiş olan dokümanların incelendiği aşamadır.

- İlgili bilgi vericilerin tanımlanması: Araştırma yaparken bilgi alınacak kaynakların, görüşülecek, mülakat yapılacak kişilerin belirlendiği aşamadır.

- Veri toplama ve sonraki bilgi kaynaklarının tanımlanması: Araştırmaya ilişkin bilgi, kanıt ve notların toplandığı aşamadır.

- Çalışmanın bitirilmesi: Araştırma konusunu açıklamak için yeterli bilgi ve kanıta ulaşılan ve çalışmanın sonlandırıldığı aşamadır $(2,12)$.

\section{4. İz Sürme Yönteminde Örneklem Seçimi}

İz sürme yönteminde örneklem seçiminde genellikle amaca yönelik örnekleme tercih edilmektedir. Amaca yönelik örnekleme; özellikle hedefin daha küçük bir örneklemden daha geniş bir popülasyona genellemek olmadığı süreç izleme yöntemine çok uygundur. Bununla birlikte, buradaki soru, süreç izleme projeleri için en uygun olan belirli bir amaca yönelik örneklemenin olup olmadığıdır (4). Bu soruyu cevaplamak için araştırmacılar kullanmak istedikleri kriterleri göz önünde bulundurmakla yükümlüdür, bu da projeden projeye farklılık gösterebilir. Bu yöntemle, kartopu örnekleme metodu özellikle uygundur. İtibar ölçütlerine dayanan bir örnek oluşturmak için en uygun yöntem, araştırma konusuna olan bilinen ilgilerine dayanarak katılımcıların bir başlangıç alt kümesini tanımlamaktır. Daha sonra bu katılımcıların bir liste sunmalarını sağlayarak bir zincir sürecini başlatmaktır. Araştırmacılar; sürece bilinen katılımlarına göre katılımcıları, özellikle bir projenin ilk aşamalarında, bir tür amaçlı örnekleme ile seçecektir (4).

\section{5. İz Sürme Türleri}

Beach ve Pedersen iz sürme türlerini teori testi, teori oluşturma ve sonuç açıklama olmak üzere üç farklı şekilde tanımlamıştır ve bu üç çeşidi farklı kılan özellikleri aşağıdaki gibi belirtmiştir $(13,14)$ :
- Araştırmanın teorik ya da olgu merkezli tasarımı olması

- Araştırmanın teorik nedensel mekanizmaları test etmeyi veya inşa etmeyi amaçlaması

- Araştırmacıların nedensel mekanizmaların genelliğine dair anlayışları

- Sonuç sürecinin izahının açıklanması, yapılacak açıklamanın yeterliliği hakkında çıkarımlar yapılması

\subsubsection{Teori testi}

Amaç; varsayımsal bir nedensel mekanizmanın mevcut olup olmadığını test etmektir. Mevcut teorileşmeye dayanarak $\mathrm{X}$ ve $\mathrm{Y}$ arasindaki bir nedensel mekanizma kavramsallaştırmaya çalışılır. Pratikte teori testi özellikle ampirik testlerin operasyonelleştirilmesi ile ilgili olarak, ampirik testlerin uygulanmasında, teorinin geçerli olup olmadığını görmemiz gereken kanıtlarla ilgili olaya özgü ampirik tahminler yapmak için indükleyici unsurlara sahiptir (14).

\subsubsection{Teori oluşturma}

İki farklı araştırma durumunda kullanılır (14):

- $\quad \mathrm{X}$ ve $\mathrm{Y}$ arasında bir korelasyon olduğunu bildiğimiz zaman, ancak bize rehberlik edecek bir kuramımız olmadığı için ikisini (X-Y-merkezli teori binasını) birbirine bağlayan potansiyel mekanizmalar konusunda karanlıkta olduğumuzda kullanırız.

- Bir sonucu (Y) bildiğimiz halde, nedenlerden emin olmadığımızda (Y-merkezli teori oluşturma) Y'den geriye doğru bir X'in varlığını izler ve bu çalışmayı $\mathrm{X}-\mathrm{Y}$ merkezli bir analize dönüştürür. Burada izlenen şey, bir vakalar topluluğu boyunca mevcut olması beklenen teorik bir nedensel mekanizmadır.

\subsubsection{Sonuç açıklama}

Söz konusu sonucu üreten sistematik ve duruma özel nedensel mekanizmaların karmaşık etkileşimini izlemeyi amaçlayan yinelemeli bir araştırma stratejisidir. Açıklama, özel durumdan ayrı tutulamaz. Teorik mekanizmalar bu nedenle, işlevi belirli bir sonucun olası en iyi açıklamasının oluşturulmasına yardımcı olan buluşsal araçlar olarak görülür (14). 


\subsection{Genelleştirilebilirlik ve Süreç İzleme}

Nedensel mekanizmalar belirli durumlarda işlevsel hale getirildiğinden süreç takibi bir iç analiz yöntemidir. $\mathrm{Bu}$ nedenle genelleme yapmak sorun yaratabilir. Vaka çalışması metodolojistleri, bir hipotezin güçlü bir şekilde teyit edildiğini ve zorlu bir test vakasını ya da bir önceliği açıklamanın en muhtemel göründüğü bir durumu açıkladığ 1 takdirde genellenebilir olabileceğini iddia etmişlerdir. Tersine, bir hipotezin en olası bir vakayı açıklamadaki başarısızlığı, ona olan güvenimizi büyük ölçüde azaltır (7).

\section{7. İyi Bir İz Sürme İçin Dikkat Edilmesi Gerekenler}

Bennett ve Checkel iz sürme yönteminin iyi uygulanması için önerilerde bulunmuşlardır $(7,15)$ :

- Ağı alternatif açıklamalar için yaygın olarak yayınlayın.

- Alternatif açıklamalara eşit mesafede olun.

- Delil kaynaklarının potansiyel yanlılıklarını düşünün.

- Vakanın alternatif açıklamalara en çok veya en az ihtimal olup olmadığını dikkate alın.

- Ne zaman başlayacağınıza dair makul bir karar verin.

- Farklı ve ilgili kanıtları toplama konusunda gözü kara olun, ancak ne zaman duracağınıza dair makul bir karar verin.

- Araştırma hedefi için yararlı ve uygun olduğunda, süreç karşılaştırması ile süreç izlemeyi birleştirin.

- Endüktif analizlere açık olun.

- “Açıklamam doğruysa, sonuca giden belirli süreç ne olacak?” Sorusunu sormak için kesinti kullanın.

- Kesin süreç takibinin iyi olduğunu, ancak tüm iyi süreç takibinin kesin olmadığını unutmayın.

\subsection{Sağlıkta İz Sürme Tekniğinin Kullanımı}

İz sürme tekniği, sağlık akreditasyonu için önemli bir değerlendirme metodudur. Kayıtların kılavuzluğunda gerçek bir hastanın hastanedeki yolculuğunu izler. Kalite ve hasta güvenliği ile ilgili en kritik alanları hem birleştirilmiş hem de kesitsel olarak incelemeye olanak tanır $(16,17)$.

Joint Commission International bir sağlı kurumunda değerlendirmenin birçok süreçte ne şekilde yapılması gerektiğine ilişkin kılavuzlar yayınlamaktadır.

İz sürme üç türde tanımlanır (18):
1.8.1. Hasta İzleme: Hastane içerisinde münferit bir hastanın tedavi yolunu izler.

1.8.2. Sistem İzleme: Hastanedeki bir süreci başından sonuna kadar izler.

1.8.3. Multidisipliner İz sürme: Hasta güvenliği gibi birçok standart ile ilişkili bir alanda iz sürmeye yöneliktir.

\section{Kan Transfüzyonu Sürecinde İz Sürme Yöntemi Uygulama Örneğindeki Bulgular}

Kan ürünün Kızılay'dan Kan Merkezi'ne tesliminden hastaya ulaşımına ya da imhasına kadar kanın barkod numarası üzerinden izlenebilir olduğu gereç ve yöntem bölümünde bahsi gecen kayıtlarda çapraz karşılaştırmalar yapılarak tespit edilmiştir.

Kan Merkezi Sorumlu Hekimi ile yapılan görüşmede sahada yaşanan aksaklıkların ya da ramak kala olayların sözel olarak bildirildiği, bekletmeden gerekli düzeltme ve iyileştirmelerin yapıldığı, yönetimin gerekli liderliği gösterdiği ve hastanede kan transfüzyonu ile ilgili şimdiye kadar istenmeyen bir olay görülmediği belirtilmiştir.

Kan Merkezi Sorumlu Hekimi ile görüşülerek hastanenin kan ihtiyacının ve hali hazırda tutulması gereken stok miktarının hastalarının özellikleri ve güvenliği düşünülerek belirlendiği gözlenmiştir.

Kan ve kan ürünlerinin transferinin kanın uygulanacağı servisin hemşireleri tarafindan gerçekleştirildiği, standartta belirtilen özelliklerde taşıma kaplarının kullanıldığ görülmüştür.

İncelenen beş hasta dosyasında kan transfüzyonu süreci ile ilgili aşağıdaki bilgilere ulaşılmıştır:

- Hekim imzası olmayan onam formu oranı: $3 / 5=\% 60$

- Hasta imzası olmayan onam formu oranı: $1 / 5=\% 20$

- Onam Formlarında tarih ve saat bulunma oranı: $0 / 5=$ $\% 0$

- Orderda belirtilen kan transfüzyonu işlemi oranı: 0/5= $\% 0$

- Transfüzyon öncesi 2 sağlı çalışanı kontrolünün olmasi: $2 / 5=\% 40$

- Beş hastanın tamamında bakım planlarında kan transfüzyonu ile ilgili özel durumlar yansıtılmamıştır. $\% 0$ 
- Kan Transfüzyon İşleminde hasta rızasının alınması ile ilgili farklı günlerde farklı transfüzyon işlemleri için ayrı onam alınmamıştır. İncelenen dosyaların tamamında birden çok transfüzyon işlemi olmasına karşın tek bir onam olduğu görülmüştür.

- Tespit edilen bir başka uygunsuzluk formdaki kontrol kısmında orderların hiçbirinde transfüzyon isteminin olmamasına karşılık kontrol yapan sağlık çalışanının uygun diye işaretleme yapmasıdır. $\mathrm{Bu}$ yapılan kontrol ettim işaretlerinin ezbere yapıldığı izlenimini uyandırmaktadır.

Transfüzyon İzlem Sürecinin değerlendirilmesinde toplam 20 Transfüzyon İzlem Formu incelenmiştir:

- Transfüzyon öncesi iki sağlık çalışanı kontrolünün olmas1 oran1: $5 / 20=\% 25$

- Tarih belirtilmeyen form oranı: $1 / 20=\% 5$

- İmza bulunmayan form oranı: $1 / 20=\% 5$

\section{SONUÇ VE TARTIŞMA}

Süreç takibinin amacı iyi tanımlanmış ve spesifik olaylar ve süreçler hakkında bilgi elde etmektir. Temel amaç, daha geniş bir evrene yayılmak yerine, incelenen az sayıdaki vakadaki sonucu açıklamaktır (4). Süreç izleme, tanımlayıcı ve nedensel çıkarımın temelini sağlayan tanısal kanıtlar bulmayı gerektirir. Araştırmacının, belirli bir kanıt parçasının tanısal olduğunu tespit edebilmesi, bu kanıt parçasından yola ç1karak hangi kanıtların ve olayların incelenmesi, kimlerle görüşülmesi gerektiğini kestirebilmesi önceki bilgilerine ve araştırma yapılan konudaki tecrübesine dayanır (6).

Sağlıkta iz sürme yönteminin akreditasyon sürecinde bir değerlendirme metodu olarak kullanıldığı görülmektedir. Sağlıkta iz sürme; hasta izleme, sistem izleme ve multidisipliner iz sürme olarak karşımıza çıkmaktadır. (17) Ulusal ve uluslarası literatürde yapılan taramalarda kan transfüzyonu sürecinde iz sürmeyi anlatan bir çalışmaya rastlanmamıştır. Ancak akreditasyon kuruluşlarının iz sürme ile ilgili sağlık hizmetlerinde birçok süreçle ya da hasta bazlı iz sürme ile ilgili rehberler oluşturduğu ve denetim yöntemlerini anlattığ 1 görülmektedir.

$\mathrm{Bu}$ çalışmada kan transfüzyon merkezi olan bir hastanede Sağlıkta Akreditasyon Standartlarından 'Transfüzyon öncesi, esnası ve sonrasında hasta güvenliğini sağlamaya yönelik tedbirler alınmaktadır' standardı çerçevesinde sistem iz sürme tekniği ile inceleme yapılmıştır. Bulgulara bakıldığında standardın gerektirdiği yapılanmanın incelenen hastanede tanımlanmış olduğu ancak henüz uygulama noktasında eksikliklerin olduğu sonucuna varılmaktadır.

İz Sürme Yöntemi sosyal bilimlerde kullanılan bir yöntem olarak bilinmesine karşın sağlık alanında da özellikle kalite denetimlerinde süreçlerin izlenmesinde kullanılırken, bu çalı̧̧mada ilk kez "kan transfüzyonu" modeli için iyi bir uygulama modeli oluşturmuştur. 
Ek 1

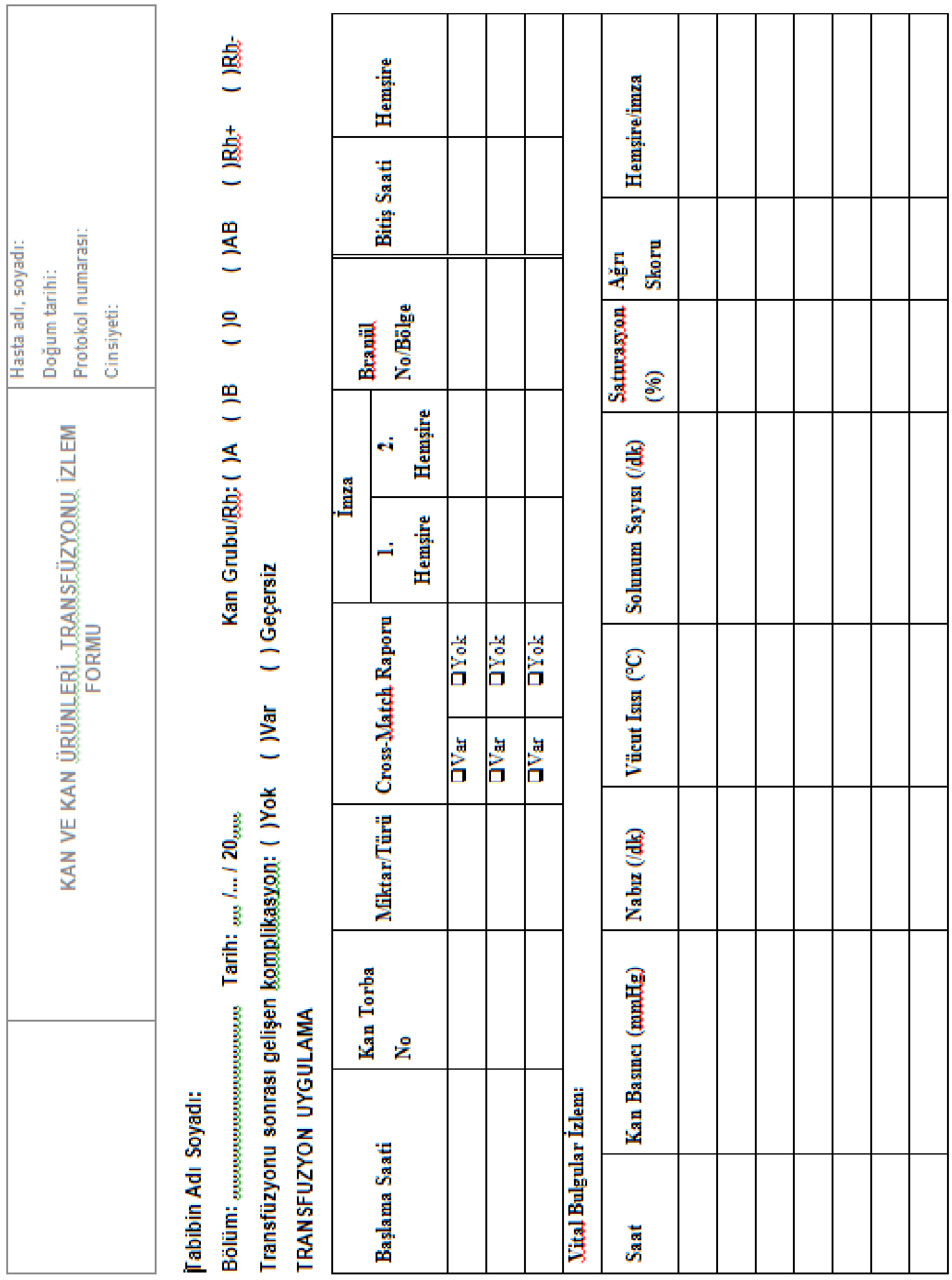




\section{KAYNAKLAR}

1. Bennett A. ve Elman C. Complex causal relations and case study methods:the example of path dependence. Advance Access Publication. June 72006.

2. İşçi E. Nitel araştırma yöntemleri. http://emreisci.blogspot. com.tr/2008/11/nitel-aratirma-yntemleri.html. 2008 [Erişim Tarihi:8.3.2018]

3. Hornby, P. ve Symon, G. Tracer studies (Eds: C. Casselland G. Symon). Qualitative Methods in Organisational Research: A Practical Guide. 1994, 167-186.

4. Tansey O. Process tracing and elite interviewing: a case for non-probability sampling, University of Reading. 2007.

5. Rohlfing I. Varieties of process tracing and ways to answer why-questions. European Political Science. 2013: 12 (1): 3139

6. Collier D. Understanding process tracing. Political Science and Politics 2011: 44, No4: 824-830

7. Bennett A. ve Checkel J T. Strategies for social 1nquiry :process tracing: from metaphor to analytic tool. Cambridge University Press. 2015.

8. Kessner D. M., Kalk C. E. ve Singer J. Assessing health quality - the case for tracers. New England Journal. 1973: Vol:288, No:4, 189-194.

9. Hall P. A. Tracing the progress of process tracing. European Consortium for Political Research. 2013.

10. Kittel B. ve Kuehn D. Introduction: reassessing the methodology of process tracing. European Political Science. 2013: 12 .

11. Zaks,S. Relationships among rivals (RAR): a framework for analyzing contending hypotheses in process tracing. political analysis. Political Analysis Volume 25, Issue 3 July 2017, pp. 344-362

12. Wordpress https://tekniksosyoloji.wordpress. com/2010/04/26/nicel-ve-nitel-arastirma/. 2010. [Erişim Tarihi: 8.3.2018]

13. Beach D, Pedersen R B. What is process tracing actually tracing? The three variants of process tracing methods and their uses and limitations. Paper prepared for presentation at The American Political Science Association annual meeting. Washington, USA. 2011: September 1-4.

14. Beach D. ve Pedersen R B. Process-tracing methods: foundations and guidelines, The University of Michigan Press. 2013.

15. Anderl F. Review: Andrew Bennett \& Jeffrey T. Checkel (Eds.). Process tracing: from metaphor to analytic tool. Forum qualitative social research. 2015: Volume 16, No. 3, Art. 18 September

16. Türkiye Sağlık Enstitüleri Başkanlığı Sağlık Hizmetleri Kalite ve Akreditasyon Enstitüsü. Sağl1kta Akreditasyon Standartlar1 Hastane Seti / v1.1. 2015.

17. Beylik, U. Sağlıkta akreditasyon denetim yöntemi: Türkiye Sağlık Hizmetleri Kalite ve Akreditasyon Enstitüsü uygulaması. Sağlıkta Kalite ve Akreditasyon Dergisi, 2018, $1(1), 6-13$.

18. Joint Commission International. Accreditation Survey Activity Guide For Health Care Organizations Issue Date: February 62017.

19. George A. L. ve Bennett A. Case studies and theory development in the social sciences. London: MIT Press. 2005.

20. Sağlık Bakanlığı. Ulusal kan ve kan ürünleri rehberi. 2009. 